\title{
La Archivística en el ámbito de las organizaciones empresariales: estado de la cuestión y propuestas de actuación
}

\author{
Miguel Ángel del Prado Martínez \\ CEPYME Aragón (España)
}

\subsection{Resumen}

Estado de la cuestión sobre la archivística en las organizaciones empresariales. Tras un acercamiento a la historia del asociacionismo empresarial español desde finales del siglo XVIII hasta la actualidad, se examinan las distintas fuentes de información existentes sobre los archivos y los fondos documentales generados por las organizaciones empresariales, se expone el estado de la cuestión de la Archivística en este ámbito, se analiza el marco legal que ha regido a estos archivos y se señalan una serie de características de las organizaciones empresariales que han condicionado el desarrollo de sus archivos. De esta manera se consigue un retrato de la situación archivística y se remarcan los aspectos más problemáticos: falta de profesionales, vacío legal en materia documental, ausencia de información y de bibliografía específica, peligro de desaparición de la documentación con valor histórico. Finalmente, se realizan una serie de propuestas de actuación como la integración del archivo junto a la biblioteca y el centro de documentación dentro del sistema de gestión documental, la consideración del archivo como una pieza fundamental del sistema organizativo y de funcionamiento interno de las organizaciones, la necesidad de una visión global que abarque el ciclo vital completo de la documentación y que integre a todos los soportes documentales. Se concluye con unas reflexiones sobre el valor de la documentación histórica y la necesidad de arbitrar medidas que posibiliten su conservación y puesta en servicio.

Palabras clave: Archivos. Organizaciones empresariales.

\subsection{Abstract}

State of the question on businesss organizations archives. After an approach to the history of the Spanish businesss associationism from the end of the 18th century to the present, the different information sources, archival repositories, state of the question, legal frame and main characteristics are examined. A landscape of the situation is obtained and the most problematic aspects are underlined: lack of professionals, legal emptiness in documentary issues, absence of information and specific bibliography, and the danger of disappearance of documentation

Scire. $10: 1$ (en.-jun. 2004) 185-216. 
with a historical value. Finally, a series of proposals is offered: integration of archives with libraries and documentation centers into the information management system, the consideration of the archive like a basic piece of the organizational system and the internal operation, the need of a global vision that includes the complete vital cycle of the documentation integrating all the different media. As a conclusion, the value of historical documentation and the need to arbitrate measures to make possible their conservation and good shape are discussed.

Keywords: Archives. Enterprise organizations

\section{Las organizaciones empresariales}

\subsection{Definición}

Las organizaciones empresariales son entidades asociativas de derecho privado que desde su propia decisión y voluntad agrupan y estructuran en su conjunto a empresarios de cualquier tamaño y rama de actividad y que tienen por objeto la representación, defensa y promoción de los intereses económicos y sociales de sus asociados, esto es de las empresas afiliadas directa o indirectamente. Aunque estrechamente relacionadas hay que diferenciarlas de las Cámaras de Comercio, Industria y Navegación, al ser corporaciones de derecho público configuradas como órganos consultivos y de colaboración con las administraciones públicas, sin menoscabo de los intereses privados que persiguen. Tampoco deben confundirse con las empresas, pues aunque las conformen empresarios, sus fines, organización y legislación son completamente diferentes.

\subsection{Evolución histórica}

En este recorrido seguiremos la obra de Ana María García Femenía (2002), El asociacionismo empresarial en España.

\subsubsection{Orígenes S. XVIII-XIX: Defensa de intereses económicos}

El asociacionismo empresarial surge en España a finales del siglo XVIII, fraguándose durante el siglo XIX en el tránsito del sistema gremial al sistema de producción capitalista. El origen de las primeras asociaciones se encuentra en la defensa de los intereses económicos de los empresarios, especialmente la protección de sus productos frente a la competencia extranjera. Es el caso de la Real Compañía de Hilados de Algodón, creada en 1772 en Barcelona, y considerada la primera asociación empresarial española, y que surge para fomentar el hilado de algodón en Cataluña frente al que llegaba de las colonias. Finalidades semejantes tendrán el Cuerpo de Fabricantes de Hilados y Tejidos de Algodón y la Junta de Pintados creados a finales del siglo XVIII. En 1820 surge la Comisión de Fábricas de Hilados, Tejidos y Estampados de Algodón de la unión de la Real Compañía de Hilados de Algodón y la Junta de Pintados.

Scire. $10: 1$ (en.-jun. 2004) 185-216. 
A pesar de una aparición tan temprana del asociacionismo empresarial, habrá que esperar hasta 1869 para que en España se reconozca el derecho de asociación, y no será hasta el año 1887 con la aprobación de la ley de asociaciones cuando se contó con la cobertura legal que permitió la constitución de los distintos tipos de asociaciones, y entre ellas las empresariales. En 1889, dos años más tarde de la publicación de la ley de asociaciones surge, a partir del embrión de la Real Compañía de Hilados de Algodón, Fomento del Trabajo Nacional, una asociación empresarial que ha perdurado hasta nuestros días. En 1894 se constituía en Bilbao la Liga Nacional de Productores, la primera gran asociación de empresarios tanto por el ámbito geográfico que abarcaba - Vizcaya, Cataluña, Asturias, Madrid, Málaga, Sevilla, Navarra, Valladolid, Salamanca- como por los sectores que agrupaba - textil, siderometalúrgico, hullero, triguero.

\subsubsection{Siglo XX: Resistencia frente al movimiento obrero: "las patronales"}

Con el agravamiento de la llamada cuestión social en la segunda década del siglo XX, aparecen las "organizaciones patronales" de defensa de intereses frente a un movimiento obrero muy organizado y activo. Algunas de estas nuevas asociaciones consiguen una cobertura nacional. Es el caso de la Confederación Patronal Española constituida en 1914 con federaciones en Madrid, Barcelona y Zaragoza y que ha sido reconocida como la primera organización empresarial de ámbito estatal creada en España. Pero no sólo se dio la confrontación con los obreros, así en 1912 se constituía en Madrid la Federación Gremial Española, cuyos miembros eran pequeños y medianos empresarios que creían compartir un espacio común con los obreros, y añoraban el "gremio" como organización corporativa. También es de destacar la Federación Nacional de Industrias, creada en 1923, y que se puede considerar como una excepción, al alcanzar el ámbito nacional defendiendo intereses económicos como eran desplazar la competencia extranjera con el objeto de aprovechar las inversiones en obras públicas anunciadas por la Dictadura de Primo de Rivera. Con la II República, la Constitución de 1931 reconoce el derecho de asociación o sindicación aprobándose en 1932 la ley de asociaciones profesionales, de patronos y obreros. En este periodo es de destacar la constitución de la Unión Nacional Económica, entidad apolítica que trató de aunar intereses en torno a lo que podría ser un ideario colectivo de la patronal y la promoción de un pensamiento orgánico para todo el empresariado. Ha sido considerada la primera asociación general de empresarios surgida en España.

\subsubsection{Franquismo}

Un importante giro se produce tras la guerra civil. El régimen de Franco estableció un sistema corporativo que englobaba a todos los factores de la producción en una Organización Sindical a la que todos los "productores" - empresarios, trabajadores y técnicos - pertenecían obligatoriamente, prohibiendo la existencia 
de cualquier tipo de asociación para la defensa de intereses profesionales o de clase "lleven o no la denominación de sindicatos, asociaciones obreras, patronales, gremiales, etc." (artículo2 de la Ley de Unidad Sindical de 1940). La estructura sindical preveía dos grandes líneas, la política o de mando - dirigida por la Delegación Nacional de Sindicatos - y la representativa o socioeconómica - formada por los sindicatos nacionales - , que tendrían a nivel local, comarcal, provincial y nacional, secciones económicas (englobarán a los empresarios) y secciones sociales (participarán trabajadores). Ambas líneas se unían en el Congreso Sindical.

A partir de los años cincuenta, aparece un incipiente asociacionismo empresarial, que aunque incluido dentro de la Organización Sindical, gozó de una relativa autonomía y cuyo reconocimiento permitió el surgimiento de toda una estructura organizativa empresarial que ha llegado en gran parte hasta nuestros días. Los objetivos de estas organizaciones fueron en principio meramente económicos, pero tras la aprobación en 1958 de la Ley de Convenios Colectivos Sindicales muchas de ellas pasaron a tener competencias en materia de negociación colectiva y comenzaron el viraje hacia un tipo de organización empresarial no estrictamente económica sino también laboral En 1964 se aprobó la Ley general de asociaciones, y aunque dejaba fuera a las asociaciones empresariales y de trabajadores - por considerarlas incluidas en el ámbito de actuación de la Organización Sindical-, algunas como Círculo de Economía o Fomento de Trabajo Nacional se acogieron a ella para existir fuera de la Organización Sindical. La Ley sindical de 1971 vino a dar legalidad a la existencia de una realidad asociativa que claramente había desbordado el marco de la organización sindical tal y como había estado configurado. Las antiguas secciones económicas y sociales se convirtieron en Uniones de Empresarios y de Trabajadores, dentro de las cuales se integraron las distintas asociaciones. Las Uniones recibieron personalidad jurídica y capacidad de obrar en funciones como representar, gestionar y defender los intereses económicos, sociales, laborales y profesionales de sus miembros, así como para la iniciativa y negociación en su ámbito de convenios colectivos sindicales. Las Uniones de empresarios fueron embriones de importantes organizaciones empresariales posteriores. Además se crearon los Consejos de Trabajadores y de Empresarios, que podían ser de ámbito provincial o nacional. El Consejo Nacional de Empresarios se configura como una verdadera confederación empresarial al aglutinar en su seno a las Uniones empresariales que existían por sector y a los Consejos Provinciales de Empresarios.

\subsubsection{Democracia}

Tras la muerte de Franco se reconoció oficialmente la libertad de asociación a trabajadores y empresarios mediante la Ley de Asociación Sindical de 1977, lo que supone el inicio del asociacionismo democrático empresarial. Al reinstaurarse la democracia existía todo un tejido asociativo que cubría prácticamente

Scire. $10: 1$ (en.-jun. 2004) 185-216. 
todos los niveles posibles. El asociacionismo sectorial tenía su estructura en casi todos los sectores de la actividad económica; y en el asociacionismo territorial se habían desarrollado de forma similar numerosas entidades que, aún vinculadas formalmente a la Organización Sindical, habían conseguido actuar como embriones de auténticas asociaciones voluntarias. Por ello, aunque la idea que vino a primar fue la ruptura con la situación anterior, considerando necesario buscar nuevas vías para asociarse, en realidad esa ruptura se produjo más en la forma que en el fondo. Así el mapa asociativo empresarial, contando con el legado del sistema anterior, se fue estructurando en torno a dos polos principales: el sectorial y el intersectorial. El sectorial, de rama o categoría profesional - cuyas organizaciones en muchos casos provenían del sindicalismo vertical - agrupa a las empresas que tienen en común un producto o conjunto de productos, un mercado o una profesión. Esta estructura de ramas o sectores comprende un gran número de asociaciones, federaciones o confederaciones de distintos niveles territoriales, desde el nacional hasta el local, que abarcan desde actividades muy concretas y especializadas hasta grandes sectores con numerosas ramas de actividad. Por su parte, el territorial intersectorial agrupa a las organizaciones, ya sean territoriales o sectoriales, de un ámbito territorial determinado. Existen organizaciones intersectoriales de ámbito nacional, autonómico, provincial, comarcal e incluso local. En lo más alto de la estructura empresarial española están Confederación Española de Organizaciones Empresariales (CEOE) y la Confederación Española de la Pequeña y Mediana Empresa (CEPYME), organizaciones intersectoriales con competencia en asuntos comunes a todas las empresas españolas. En torno a los dos polos, se produce un multiasociacionismo empresarial en virtud del cual las empresas pueden estar asociadas directamente a varias entidades asociativas e indirectamente a otras. Ese multiasociacionismo se reproduce en las propias asociaciones, que se integran a su vez en otras organizaciones empresariales tanto en el ámbito territorial como en el sectorial.

Este complejo mapa asociativo está formado por una innumerable sucesión de entidades asociativas de distintos ámbitos sectoriales y niveles territoriales, todas ellas con personalidad jurídica propia y constituidas en virtud de la Ley de asociación sindical de 1977. Según la Guía de las organizaciones empresariales españolas (1999) en la actualidad hay 5.759 organizaciones empresariales.

\section{Situación actual de los archivos}

\subsection{Información sobre sus fondos documentales}

Las organizaciones empresariales desde el momento de su constitución -y como consecuencia del desempeño de las actividades que les son propias - han generado un conjunto de documentos que, de conservarse, conformarán sus respectivos archivos. Por lo tanto, debería haber tantos archivos como organiScire. $10: 1$ (en.-jun. 2004) 185-216. 
zaciones empresariales, lo que significa que en la actualidad deberían existir 5.759 archivos de organizaciones empresariales, a los que habría que añadir los de las organizaciones ya desaparecidas. A pesar de un número de archivos supuestamente tan abultado la información que se puede obtener sobre ellos es verdaderamente parca, como hemos comprobado tras la consulta del Censo Guía de Archivos de España e Iberoamérica, de la información ofrecida por las comunidades autónomas y la consulta a una serie de archivos estatales.

\subsubsection{Censo Guía de Archivos de España e Iberoamérica}

La principal fuente de información sobre los archivos españoles es el Censo Guía de Archivos de España e Iberoamérica, que viene elaborando desde el año 1977 el Centro de Información Documental de Archivos (CIDA) dependiente de la Subdirección General de los Archivos Estatales con la colaboración de las distintas Comunidades Autónomas españolas así como de los países Iberoamericanos. El Censo Guía de Archivos proporciona información tanto de los centros de archivo como de la documentación que custodian a nivel de fondos y colecciones. Desde el punto de vista geográfico, además de los archivos radicados en España, el Censo Guía de Archivos registra información de Argentina, Bolivia, Brasil, Colombia, Costa Rica, Cuba, Chile, Guatemala, México, Nicaragua, Paraguay, el Salvador y Venezuela. La información del Censo Guía de Archivos está incluida en una gran base de datos consultable en Internet a través de la página web de la Subdirección General de los Archivos Estatales. La base de datos del Censo Guía presenta tres pantallas de búsqueda: a) Directorio de archivos, desde la que se pueden consultar los centros de archivo censados; b) Fondos documentales, desde la que se pueden realizar consultas sobre las descripciones de los fondos documentales que aquéllos conservan; y c) Archivos y fondos documentales, desde la que se pueden realizar consultas sobre los Centros de Archivo y los fondos documentales a ellos adscritos.

Entre los meses de febrero y septiembre de 2003 la hemos consultado en distintas ocasiones y utilizando distintas estrategias de interrogación, y hemos obtenido información de 41 archivos de organizaciones empresariales, 11 de ellos clasificados como "archivos patronales" (1), 27 como "archivos de asociación" (2) y 3 como "archivos empresariales" (3). Sobre cada uno de estos archivos ofrece la identificación del Servicio de Archivo - nombre del archivo, dirección, tipo de acceso, horario y los datos del responsable del archivo - , su clasificación - titularidad, gestión (pública o privada), ciclo vital, tipología del archivo-, los servicios técnicos que ofrece - taller de restauración, reproducción documental, biblioteca auxiliar-, las funciones informatizadas y el cuadro de clasificación de los fondos. Tras su análisis podemos resumir que los archivos censados son archivos centrales, carecen de responsable, no tienen informatizada ninguna función, tampoco ofrecen servicios técnicos y el acceso a la documentación es restringido.

Scire. $10: 1$ (en.-jun. 2004) 185-216. 


\subsubsection{Páginas web de las comunidades autónomas}

Las distintas Comunidades Autónomas ofrecen a través de Internet información en distinto grado sobre los archivos radicados en su comunidad autónoma. En algunos casos se trata de los censos de archivos autonómicos, en otros casos de directorios de archivos y en otros de información a nivel de guía de los principales archivos de la respectiva comunidad autónoma. Entre los meses de agosto y septiembre de 2003 analizamos los sitios web autonómicos con los resultados que se presentan en la tabla II, en la página siguiente. Tras el análisis de estos recursos sólo hemos encontrado información sobre los fondos y archivos de organizaciones empresariales en Cataluña, Euskadi, Galicia y Aragón (tabla I).

\begin{tabular}{|l|}
\hline Archivos de organizaciones empresariales \\
\hline Arxiu del Foment del Treball Nacional (Barcelona) \\
Archivo de la Federación Vizcaina de Empresas del Metal (Bilbao) \\
Archivo de la Asociación de Armadores de Altura (Bilbao) \\
Archivo de la Confederación de la Pequeña y Mediana Empresa Aragonesa (Zaragoza) \\
Archivo de la Federación de Empresarios del Metal de Zaragoza (Zaragoza) \\
\hline Fondos de organizaciones empresariales en archivos públicos \\
\hline Gremi de Fabricants de Farina de la provincia de Barcelona (Arxiu Nacional de Catalunya) \\
Unió Comercial i Industrial de Terrassa (Arxiu Històric Comarcal de Terrassa) \\
Asociación de Fomento (Arxiu Històric Comarcal d'Olot) \\
Asociación Xeral Patronal de Galicia (Archivo del Reino de Galicia)
\end{tabular}

Tabla I. Archivos empresariales españoles censados

\subsubsection{Consulta a los responsables de archivos de las Comunidades Autónomas}

En el mes de septiembre de 2003 se remitió a los responsables de las diecisiete comunidades autónomas españolas, una carta en la que se solicitaba que "nos facilitasen los datos que dispusiesen o nos dijeran donde podemos conseguirlos, tanto de los archivos de organizaciones empresariales existentes en la Comunidad Autónoma, como de los fondos documentales de dichas organizaciones que pudieran estar depositados en alguno de los archivos que conforman el Sistema de Archivos de la Comunidad Autónoma." De las nueve comunidades autónomas que respondieron - Andalucía, La Rioja, Valencia, Murcia, Extremadura, Canarias, Cantabria, Castilla La Mancha, y Navarra-, en ninguna de ellas disponían de datos sobre estos archivos. Así, desde Cantabria informaron sobre la documentación de la Organización Sindical depositada en el Archivo Histórico Provincial de Cantabria. Desde Valencia proporcionaron los datos del Instituto de la Mediana y Pequeña Industria Valenciana (IMPIVA), al cual no podemos considerar una organización empresarial sino un ente público. Desde Murcia dieron referencia de documentación conservada en el Archivo Histórico Provincial, como es la de la Cámara de Comercio o los Libros de Sociedades y Comerciantes

Scire. $10: 1$ (en.-jun. 2004) 185-216. 


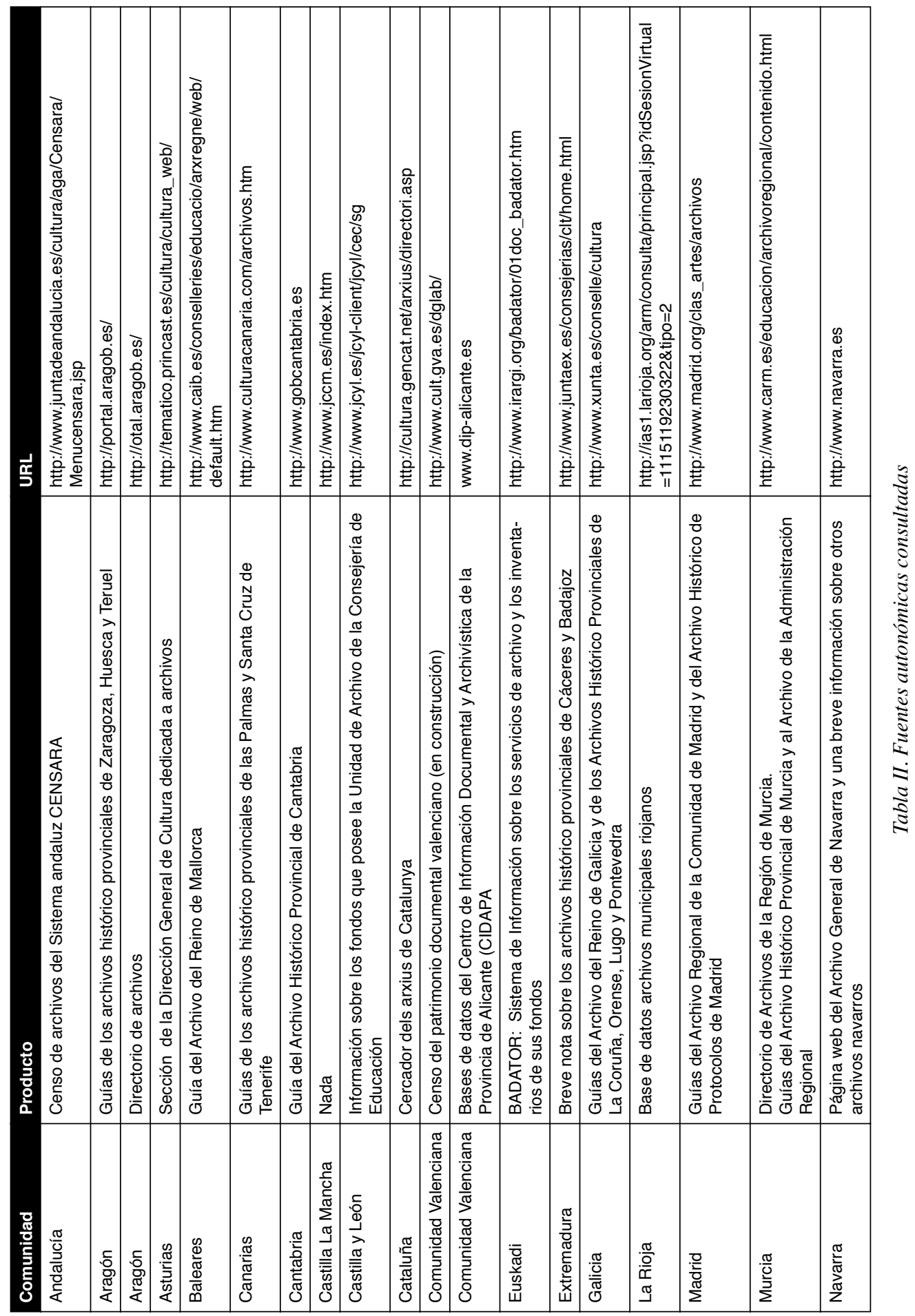


del Registro Mercantil, pero aunque relacionadas no podemos considerar como producidas por Organizaciones Empresariales. Desde Canarias remitieron el cuadro de organización de fondos del Archivo Histórico Provincial de Las Palmas. En La Rioja, Extremadura, Castilla La Mancha y Navarra nos remitieron directamente a las organizaciones empresariales, facilitándonos sus direcciones. Esta última también nos indicó la posibilidad de obtener información en el censo guía de archivos. Por su parte, desde Andalucía señalaron la posibilidad de consultar desde Internet el Censo de Archivos de Andalucía.

\subsubsection{Solicitud de información mediante correo electrónico a archivos estatales}

En busca de algún fondo documental que pudiera estar depositado en algún archivo estatal, solicitamos información a través de correo electrónico al Archivo General de la Administración, Archivo Histórico Nacional, Archivo General de la Guerra Civil Española y al Archivo de la Corona de Aragón. De todos ellos, sólo en el Archivo General de la Administración localizaron documentación relacionada con las organizaciones empresariales, pero nos señalaron que la "identificación, selección y análisis debe realizar Ud. en nuestra sala de consulta". Puestos en contacto telefónico nos indicaron que dentro del Fondo de la Organización Sindical hay documentación de la Asociación de Oliveros, Federación Española de Aceite, Federación de Fabricantes de Jabón, Federación de Aceite de Orujo y de la Unión de Olivocultores.

\subsubsection{Conclusiones}

Tras un exhaustivo análisis de las distintas fuentes de información de archivos, incluyendo la consulta directa a varios archivos y a los responsables de las comunidades autónomas, sólo hemos obtenido información de 46 archivos de organizaciones empresariales y de nueve fondos documentales conservados en archivos públicos. En conclusión, de las casi 6000 organizaciones empresariales que existen en la actualidad sólo están censados 41 archivos. Es significativo que sólo 11 de ellos están clasificados como archivos patronales, 27 bajo la clasificación más genérica de archivos de asociación y 3 de manera incorrecta como archivos empresariales. Las comunidades autónomas no han prestado demasiada atención a este tipo de archivos, por lo que sólo se obtuvo información de cinco archivos y cuatro fondos conservados en archivos públicos. Sorprende comprobar que ninguno está incluido en el Censo Guía de Archivos de España e Iberoamérica. Es, pues, significativo el desconocimiento de los responsables autonómicos sobre los archivos de las organizaciones empresariales.

El depósito de fondos documentales de las organizaciones empresariales en archivos públicos no es una práctica habitual; pues, salvo la documentación de la organización sindical, sólo hemos localizado cinco fondos en el Archivo General de la Administración y cuatro en los de las comunidades autónomas.

Scire. $10: 1$ (en.-jun. 2004) 185-216. 


\subsection{Bibliografía: Repertorios bibliográficos consultados}

La bibliografía sobre los archivos de asociaciones y la clasificación de sus fondos es escasa -tal y como señalaban en 1994 la Comisión Técnica de Archivos Históricos de la ANABAD-, pero la específica sobre los archivos de las organizaciones empresariales es prácticamente inexistente. La consulta a través de Internet de la base de datos bibliográfica del Centro de Información Documental de Archivos (CIDA) (6) no puede ser más decepcionante, no recuperándose ningún registro sobre archivos de asociaciones empresariales. No se tiene más suerte acudiendo directamente al CIDA, así a la consulta que le planteamos en el mes de febrero de 2003 obtuvimos la siguiente respuesta:

En relación con la consulta telefónica realizada por usted relativa a bibliografía sobre los archivos de organizaciones patronales, sentimos comunicarle que no tenemos ningún título que responda a esa temática.

La consulta a otras bases de datos bibliográficas de carácter más general como ISOC del Consejo Superior de Investigaciones Científicas, y los Social Sciencies Citation Index, Arts \& Humanities Citation Index y Current Contents: Arts \& Humanities - producidas por el Institute for Scientific Information (ISI) - no aportó más referencias. Sólo en la extensa bibliografía ofrecida por José Bibiano, director del Archivo de la Historia del Trabajo de la Fundación $1^{\circ}$ de Mayo, en el programa del curso de doctorado que imparte en la Universidad Carlos III de Madrid, bajo el título de "Documentos y archivos de relaciones laborales", en el apartado dedicado a "Bibliografía específica sobre archivos de empresa" hemos encontrado una referencia al trabajo sobre el archivo de Fomento de Trabajo Nacional realizado por Maluquer de Motes. La lectura de artículos sobre temas afines como los archivos de empresa nos han aportado el resto de referencias.

\subsection{Estado de la cuestión}

\subsubsection{Dependencia historicista de la archivística}

La archivística como disciplina independiente con unos principios teóricos propios y una metodología de trabajo específica ha tenido desde sus orígenes a mediados del siglo XIX una fuerte dependencia historicista que ha llevado a los profesionales hasta bien entrado el siglo XX a ocuparse en exclusiva de los fondos documentales con interés histórico. No hay que olvidar que incluso el principio fundamental de la archivística, conocido como "principio de procedencia o de respeto de los fondos" surge como un método para facilitar la investigación histórica, al mantener agrupados los documentos producidos por una institución sin mezclarlos con otros, lo que permite conocer su evolución histórica. Del mismo modo, el carácter seriado de la documentación en la que se fundamenta la metodología archivística, ha estado impulsado por los historiadores sobre todo económicos y sociales, necesitados de largas series de datos homogéneas para la

Scire. $10: 1$ (en.-jun. 2004) 185-216. 
realización de sus estudios. Ello significa que la archivística ha ido a remolque de los intereses historiográficos de cada momento, siendo los historiadores los que en buena medida han ido marcando las líneas de actuación en los archivos. Por lo tanto aquellos archivos sin interés para los investigadores del pasado han quedado relegados, y este es el caso de los archivos de las organizaciones empresariales.

Aunque en la actualidad ya disponemos de trabajos que abordan la organización de los empresarios en distintas etapas políticas y a pesar de que las propias organizaciones empresariales fundamentalmente con motivo de los aniversarios de su constitución han venido publicando estudios sobre ellas mismas (Gutiérrez Álvarez, 2001, p. 18; García Femenía, 2002, p. 309-329), lo cierto es que el interés por el asociacionismo empresarial como sujeto histórico es reciente. Hasta prácticamente la década de los 90 no se inició la recuperación del asociacionismo empresarial como objeto de estudio desde diversas disciplinas, como la sociología o la historiografía. La falta de interés de los investigadores por las organizaciones empresariales ha redundado en una desatención hacia la documentación que reflejaba sus actuaciones y su devenir histórico, y en consecuencia hacia sus archivos.

La única atención hacia estos archivos por parte de la investigación histórica ha venido de su potencial interés como fuente de información de carácter complementario para la realización de estudios fundamentalmente económicos, y más concretamente sobre la historia empresarial. Y es de destacar que estas aportaciones se han realizado desde Cataluña. Es el caso de la comunicación presentada por Jordi Maluquer de Motes sobre el archivo de Fomento del Trabajo Nacional en el Primer Congreso sobre Archivos Económicos de Entidades Privadas celebrado en Madrid en junio de 1982. En dicha comunicación describe la documentación conservada en ese archivo y apunta los temas que pueden ser estudiados con dicha documentación. A este mismo archivo corresponde el único instrumento de descripción de un archivo de organización empresarial publicado del que hemos encontrado referencia: Catálogo del Archivo y Biblioteca del Instituto de Fomento del Trabajo Nacional (Catalogo de Bibliotecas de España, 2003). Por otra parte, el interés de los archivos de las organizaciones empresariales para la historia empresarial es remarcado por Josep Fernández Trabal (1996) en un artículo dedicado a exponer las actuaciones realizadas por el Arxiu Nacional de Catalunya, en el que señala que "para hacer la historia de la empresa con rigor es necesario trascender el ámbito estricto de los archivos de empresa y poner a disposición de la investigación otra clase de documentos relacionados. Recuperar fondos de organizaciones empresariales, como el de la Asociación de Fabricantes de Harina de la Provincia de Barcelona ingresado en el Arxiu Nacional de Catalunya en 1995." También dentro del ámbito geográfico catalán se ha destacado el interés para los estudios regionales o nacionales. Así Jaime Sobreques (1982) en un análisis tipológico de los centros documentales a los

Scire. $10: 1$ (en.-jun. 2004) 185-216. 
que es preciso acudir para estudiar el regionalismo, el catalanismo o el nacionalismo, en el capítulo dedicado a "Els arxius I les biblioteques d'instituciones econòmiques" relaciona diez archivos, entre los que se encuentra el de Fomento del Trabajo Nacional (7). Los datos que aporta son muy básicos: fecha de constitución o fundación, y, en el mejor de los casos, alguna breve y muy genérica referencia a la documentación que albergan.

\subsubsection{Archivística desarrollada en archivos públicos}

La archivística se ha desarrollado principalmente en las administraciones públicas. La tarea profesional se ha realizado sobre archivos públicos o sobre fondos privados depositados en archivos públicos. Son excepciones los colectivos que han contando con profesionales en el ámbito privado, sería el caso de los archivos eclesiásticos y de los archivos nobiliarios. Es por ello que la documentación mejor conservada, estudiada y conocida del empresariado español es la correspondiente a la organización sindical del franquismo, debido a su dependencia estatal y a la conservación de su documentación en archivos de titularidad pública. No podemos considerar a la organización sindical - ni siquiera a las Secciones Económicas que englobaban a los empresarios - como asociaciones empresariales, ya que tenían un carácter obligatorio y dependían del aparato estatal. No obstante hay que tener en cuenta que dentro de ella se cobijó el asociacionismo empresarial durante cuarenta años.

La situación de los fondos documentales de la organización sindical la podemos conocer a través de dos aportaciones publicadas en 1980 y 1992 respectivamente. El primero es un artículo publicado en la revista ANABAD por María Aurelia Corral y Carmen Sierra (1980). En él, tras una breve introducción sobre la extinguida organización sindical y la creación del Archivo General de la Organización Sindical, se expone el proceso seguido para inventariar toda la documentación de la Organización Sindical - convertida en 1976 en la Administración Institucional de Servicios Socio-Profesionales (AISS) - y transferirla al Archivo General de la Organización Sindical, para finalmente enviarla a los respectivos Archivos Históricos Provinciales. El segundo es una comunicación presentada por el Grupo de Trabajo sobre la Administración Institucional de Servicios SocioProfesionales (AISS) (1992) en las Primeras jornadas sobre metodología para la identificación y valoración de fondos documentales de las administraciones públicas en el que expone el estado en el que se encontraba el proyecto de identificación y valoración de la documentación de la Organización Sindical Española.

\subsubsection{Evolución reciente de la archivística}

La archivística ha evolucionado a partir de la $2^{\mathrm{a}}$ mitad del siglo XX, apremiada por una serie de problemas comunes a las distintas instituciones: el crecimiento exponencial de la documentación que ocasiona dificultades para 
su gestión, almacenamiento y recuperación; la necesidad de atender a nuevas demandas, sobre todo de los ciudadanos que con la extensión de la democracia adquieren derecho a estar informados de las actuaciones realizadas por las administraciones y al acceso a la documentación conservada en sus archivos; y la irrupción de las nuevas tecnologías que provocan la aparición de nuevos soportes documentales. Todo esto lleva a asumir la necesidad de ocuparse del ciclo vital de la documentación, desde el mismo momento de su creación hasta el de su destrucción o conservación permanente. Se adquiere una concepción sistémica del archivo, que deja de ser el lugar donde se conserva la documentación histórica, para transmutarse en un servicio capaz de gestionar la documentación a lo largo de todo su ciclo vital mediante distintos tipos de archivos (de oficina, centrales, intermedios e históricos) que secuencialmente asumen la responsabilidad sobre la documentación y que realizarán distintas funciones atendiendo a las necesidades informativas de los usuarios.

Estos son los principios de los que parte la actuación llevada a cabo en los archivos de las organizaciones empresariales aragonesas CEPYME Aragón, CEPYME Zaragoza y FEMZ y de la que se dio cuenta en los VI Encuentros Internacionales sobre Sistemas de Información y Documentación (Ibersid 2001) (Prado Martínez , 2002).

\subsection{Marco legal}

\subsubsection{Patrimonio documental}

Las únicas disposiciones legales que afectan a los archivos de las organizaciones empresariales son las que tienen por objeto la defensa y conservación del patrimonio documental, es decir la ley 16/1985 de 25 de junio de Patrimonio Histórico Español y sus decretos de desarrollo en el ámbito estatal y las respectivas leyes de archivo o de patrimonio documental en las distintas comunidades autónomas recogidas en el repertorio de Legislación básica (2005) de la Universidad de Alicante o de Legislación cultural (2005) del Ministerio de Cultura.

En líneas generales las disposiciones estatales y autonómicas son coincidentes. Tanto la ley 16/1985 de Patrimonio Histórico Español como las posteriores leyes autonómicas consideran integrantes del patrimonio documental a los documentos con una antigüedad superior a cuarenta años - excepto Andalucía, que extiende el plazo a los cincuenta años - generados, conservados o reunidos en el ejercicio de sus actividades por las entidades y asociaciones de carácter político, sindical o religioso, y por las entidades, fundaciones y asociaciones culturales y educativas de carácter privado. Aunque no se menciona explícitamente a las organizaciones empresariales, hemos de considerarlas incluidas dentro de estas categorías. La excepción la marcan las leyes canaria, madrileña, valenciana y riojana que sí mencionan expresamente a los documentos de las asociaciones

Scire. $10: 1$ (en.-jun. 2004) 185-216. 
empresariales. Así mismo, las distintas comunidades autónomas se reservan la posibilidad de declarar patrimonio documental a documentos que no tienen la antigüedad señalada en virtud de su valor. Por otra parte, las leyes autonómicas contemplan la posibilidad de incluir a los archivos privados $-\mathrm{y}$, por lo tanto, a los archivos de las organizaciones empresariales - dentro de los respectivos sistemas archivísticos autonómicos. En general se reconocen dos vías: una para los archivos de titularidad privada considerados de uso público por recibir de los poderes públicos determinadas subvenciones o ayudas - y que por ello formarán parte del sistema archivístico autonómico-; y otra para aquellos archivos de titularidad privada que, a petición de sus propietarios y previa resolución favorable del organismo autonómico competente, decidan integrarse en el sistema archivístico.

Aquellos archivos de organizaciones empresariales que contengan documentos considerados patrimonio documental o que estén integrados dentro del sistema archivístico de su comunidad autónoma, adquieren una serie de obligaciones, entre las que se pueden señalar: a) la conservación y custodia en condiciones adecuadas de la documentación; b) facilitar la inspección a los organismos competentes para comprobar la situación en la que se encuentran; c) permitir la consulta pública de la documentación; d) En algunas comunidades autónomas (Aragón, Castilla La Mancha, Cataluña, Madrid, Murcia), la obligación de organizar y describir los archivos o, en su caso, de permitir que esas labores sean realizadas por personal especializado designado por la administración competente; e) conservar integra su organización, prohibiéndose su desmembración; f) restaurar los documentos deteriorados o convenir su restauración; y g) comunicar las enajenaciones de documentación o cambio de titularidad. Respecto a la consulta pública se suelen establecer dos niveles de obligación: uno para los archivos privados de uso público, obligados a posibilitar un acceso general a los documentos con las limitaciones establecidas en la legislación de acceso a la documentación pública; y otro para los archivos privados que no sean de uso público, los cuales deberán permitir la consulta de la documentación histórica por los investigadores, previa solicitud razonada, estableciendo los titulares de manera discrecional las circunstancias generales de dicha consulta. El incumplimiento de estas obligaciones, previo requerimiento de la administración competente, puede suponer el depósito temporal de la documentación en un centro público e incluso su expropiación forzosa. Las contraprestaciones que reciben los titulares de estos archivos no suelen ser muy grandes. Al margen de las ayudas y subvenciones que en su momento se les puedan conceder, las acciones de la administración se limitan a atender a la formación permanente y actualización profesional del personal de los archivos integrados en el sistema y al apoyo técnico a la gestión documental. 


\subsubsection{Producción documental}

Se puede afirmar que hasta el año 2002, las organizaciones empresariales no han estado obligadas legalmente a conservar ningún tipo de documentación, ni siquiera de carácter fiscal o contable. El soporte legal de las asociaciones empresariales es la Ley 19/1977, de 1 de abril, sobre regulación del derecho de asociación sindical, a cuyo amparo surge el asociacionismo empresarial democrático, y que en la actualidad es de aplicación exclusiva para estas asociaciones tras ser derogada por la ley orgánica 1/1985, de 2 de agosto, de libertad sindical. En su breve articulado, la única obligación documental que se impone es la de establecer sus propios estatutos que deberán depositarse en la oficina pública señalada al efecto para que la asociación adquiera personalidad jurídica y plena capacidad de obrar. El depósito de los estatutos fue desarrollado por el Real Decreto 873/1977, de 22 de abril, sobre depósito de los estatutos de las organizaciones constituidas al amparo de la ley 19/1977. En éste se establece las oficinas públicas en las que deben depositarse, la documentación que hay que presentar - tanto en los casos de constitución como de modificación de estatutos - , así como los contenidos mínimos de los estatutos. Regula la tramitación que se seguirá en el momento de su registro; y se establece la publicidad tanto del depósito de los estatutos - tablón de anuncios de la oficina pública, boletín oficial provincial y en su caso del Estado - como de los propios estatutos, que podrán ser examinados en la oficina en la que se depositaron por cualquier interesado.

Hay que esperar hasta el año 2002 para encontrar una ampliación de las obligaciones documentales a las que deben atenerse las asociaciones empresariales. Se trata de la ley orgánica 1/2002, de 22 de marzo, reguladora del derecho fundamental de asociación, que, aunque deja fuera de su ámbito de aplicación a los partidos políticos, los sindicatos y las asociaciones empresariales - que se regirán por su legislación específica-, establece un régimen mínimo y común para todas con carácter supletorio respecto de "cualesquiera otras que regulen tipos específicos de asociaciones". El artículo 14 recoge las obligaciones documentales y contables a las que vienen sujetos:

1. Las asociaciones han de disponer de una relación actualizada de sus asociados, llevar una contabilidad que permita obtener la imagen fiel del patrimonio, del resultado y de la situación financiera de la entidad, así como las actividades realizadas, efectuar un inventario de sus bienes y recoger en un libro las actas de las reuniones de sus órganos de gobierno y representación. Deberán llevar su contabilidad conforme a las normas específicas que les resulten de aplicación.

2. Los asociados podrán acceder a toda la documentación que se relaciona en el apartado anterior, a través de los órganos de representación, en los términos previstos en la Ley Orgánica 15/1999, de 13 de diciembre, de Protección de Datos de Carácter Personal.

3. Las cuentas de la asociación se aprobarán anualmente por la Asamblea General.

Scire. $10: 1$ (en.-jun. 2004) 185-216. 


\section{0}

Por otra parte, el artículo 34, establece que las asociaciones de utilidad pública deberán rendir las cuentas anuales del ejercicio anterior en el plazo de los seis meses siguientes a su finalización, y presentar una memoria descriptiva de las actividades realizadas durante el mismo ante el organismo encargado de verificar su constitución y de efectuar su inscripción en el registro correspondiente, en el que quedarán depositadas. Dichas cuentas anuales deben expresar la imagen fiel del patrimonio, de los resultados y de la situación financiera, así como el origen, cuantía, destino y aplicación de los ingresos públicos percibidos.

Siguiendo el trabajo de Ángel J. Navarro Gomollón y Jaime J. Navarro Lima (2003) Aspectos contables y fiscales de las asociaciones empresariales: situación actual, los documentos fiscales que están obligados a elaborar las organizaciones empresariales son la declaración del impuesto sociedades a partir del año 2002 para las organizaciones que superen determinados ingresos, la solicitud de exención del IVA y su reconocimiento por la Administración Tributaria, la declaración del IVA no exento y las declaraciones de alta y de baja en la matrícula del Impuesto de Actividades Económicas.

La ley 43/1995, de 27 de diciembre, del Impuesto de Sociedades, no impuso ninguna obligación documental a las asociaciones empresariales, al considerarlas exentas. Las posteriores modificaciones que ha sufrido la ley - a través de la ley 24/2001 de 27 de diciembre de Medidas fiscales y administrativas de orden social y la ley 26/2003 de 17 de julio, por la que se modifican la Ley 24/1988 de 28 de julio del Mercado de Valores y el texto refundido de la Ley de Sociedades Anónimas - obligan a partir del 2002 a realizar declaración de sus rentas a efectos del impuesto de sociedades a las organizaciones empresariales que tengan ingresos superiores a 100.000 euros anuales, superen los 2.000 euros anuales de ingresos correspondientes a rentas no exentas sometidas a retención o cuando las rentas no exentas que obtengan no estén sometidas a retención. Las obligaciones contables que la ley 43/1995 impone a las asociaciones empresariales como sujetos pasivos del impuesto de sociedades se limita a lo establecido en las normas por las que se rigen. Por su parte la ley 49/2002 de Régimen fiscal de las entidades sin fines lucrativos y de los incentivos fiscales al mecenazgo establece que los sujetos pasivos del Impuesto de Sociedades en todo caso llevarán su contabilidad de tal forma que permita identificar los ingresos y los gastos correspondientes a las rentas y explotaciones económicas no exentas.

Según la ley 37/1992 de 28 de diciembre del Impuesto sobre el Valor Añadido, las organizaciones empresariales están exentas del IVA para las prestaciones de servicios y las entregas de bienes accesorias a las mismas efectuadas directamente a sus asociados, siempre que no perciban de los beneficiarios de tales operaciones contraprestación alguna distinta de las cotizaciones fijadas en sus estatutos. El disfrute de esta exención requerirá su previo reconocimiento por

Scire. $10: 1$ (en.-jun. 2004) 185-216. 
la Delegación o Administración de la Agencia Estatal Tributaria en cuya circunscripción radique el domicilio fiscal del sujeto pasivo, previa solicitud del interesado. La exención no alcanzará a las entregas de bienes y prestaciones de servicios realizadas para tercero o mediante contraprestación distinta de las cotizaciones fijadas en sus estatutos. Finalmente, están exentas del impuesto de actividades económicas las entidades sin fines lucrativos, aunque dichas entidades deberán presentar declaraciones de alta y de baja en la matrícula de este tributo.

\subsubsection{Conclusiones sobre el marco legal}

Diego Navarro Bonilla (1998) ya señaló la ausencia en España de directrices y de normas reguladoras de la producción, gestión y conservación documental dentro del ámbito empresarial. Añadía que a la falta de políticas de información que permitan a las empresas disponer de normas y criterios para efectuar un tratamiento racional y homogéneo de los documentos generados, conservados y reunidos en el transcurso de sus actividades, debe sumarse el vacío de una normativa legal de carácter unitario que permitiera paliar la disparidad de actuaciones en materia documental que tienen lugar en el interior de una empresa. Esta misma situación se reproduce en las organizaciones empresariales, agravada por el hecho de que su producción documental no ha estado sujeta a ninguna prescripción legal, resultando imposible encontrar referencias legales a tipos documentales de obligado cumplimiento, a la necesidad de organizar los archivos ante inspecciones, ni indicaciones de principios de ordenación... Cada organización empresarial es libre para decidir que documentación produce, como la organiza y cuanto tiempo la conserva. Son los estatutos y reglamentos de régimen interno de cada organización los que señalan los documentos que obligatoriamente se deben producir y conservar. Igualmente, serán los criterios de orden práctico establecidos en el seno de cada organización los que señalen los plazos de conservación de la documentación, debiendo atenerse únicamente a los plazos generales que estén establecidos para los distintos procedimientos que tramiten ante las administraciones públicas: subvenciones y ayudas, planes formativos, contratación de trabajadores, Seguridad Social... En definitiva, la documentación de las organizaciones empresariales hasta que no adquiere la categoría de patrimonio documental, es decir a los 40 años de su producción, no recibe ningún tipo de protección legal. Este vacío legal hace que la preservación de los archivos de las organizaciones empresariales dependa de la dirección de cada organización empresarial.

\subsection{Condicionantes archivísticos de las organizaciones empresariales}

\subsubsection{Aspectos generales}

La situación archivística de las organizaciones empresariales viene determinada - como no puede ser de otra manera - por la propia naturaleza de estas organizaciones. La mayoría de ellas son muy pequeñas. Según la Guía de

Scire. $10: 1$ (en.-jun. 2004) 185-216. 


\section{Miguel Ángel del Prado Martínez}

organizaciones empresariales españolas el número medio de afiliados a estas organizaciones es de 275 empresas, más de la mitad con menos de cien asociados. Únicamente el 8\% tienen más de mil afiliados, siendo la mayoría de ellas federaciones y confederaciones. Por lo tanto, en la mayoría su tamaño obliga a que la estructura administrativa sea muy sencilla, limitándose en muchos a casos a una persona que realiza las distintas tareas burocráticas. Muchos de los servicios que prestan a sus asociados los realizan empresas o profesionales externos. En ocasiones incluso carecen de sede propia. Por lo tanto, en estos casos el fondo documental que generan es muy limitado y el archivo apenas adquiere relevancia.

La multiplicidad de los intereses empresariales a defender ha impuesto una situación de multiasociacionismo, que a su vez ha conllevado un fenómeno de poliasociacionismo: por un lado, de empresas; $y$, por otro, de las propias asociaciones, que se han asociado a su vez a otras entidades de ámbito mayor, o a entidades diferentes que actúan en ámbitos distintos. De este modo 479 organizaciones tienen carácter federativo - con asociaciones miembros - y 125 son confederaciones - con federaciones asociadas a las mismas. En líneas generales son las federaciones y las confederaciones las que alcanzan un mayor grado competencial y las que presentan unas estructuras organizativas más complejas; $y$, en consecuencia, serán las que tengan una mayor producción documental. Son estas organizaciones las que más problemas archivísticos tienen; y, a su vez, las más capacitadas para afrontarlos. La mayoría de las organizaciones, especialmente las federaciones y confederaciones, tienen su sede en ciudades, preferentemente capitales de provincia, destacando Madrid con 986 organizaciones, pues en ella tienen su sede la mayoría de las organizaciones de carácter nacional. Este hecho tiene unas claras repercusiones archivísticas. Así, el elevado coste del suelo -y, por lo tanto, de los edificios - en los que se encuentran las sedes de estas organizaciones, dificulta - cuando no impide - contar con el espacio suficiente para acumular la documentación, lo que obliga a la selección y destrucción sistemática de los documentos que ya no seconsideran de valor. La multiplicidad de intereses de los empresarios ha conllevado una diversidad de formas de representarlos y de competencias asumidas, lo que dificulta establecer un marco general de actuación y organización de las asociaciones empresariales. Si a este hecho añadimos la carencia de normas legales que establezcan los tipos documentales que deben producir y conservar, dan como resultado una diversidad en la documentación producida y conservada en cada organización empresarial. Por ello, se hace muy difícil elaborar un modelo general de fondo documental en las organizaciones empresariales.

\subsubsection{Encuesta enviada a las principales organizaciones empresariales}

Para tener un conocimiento más real de la situación en la que se encuentran los archivos de las organizaciones empresariales, remitimos una encuesta a las

Scire. $10: 1$ (en.-jun. 2004) 185-216. 
principales organizaciones obteniendo los siguientes resultados. En cuanto a la responsabilidad del archivo el $73 \%$ carece de archivero o responsable del archivo. La responsabilidad de la documentación recae principalmente en los propios departamentos productores de la documentación (53\%), siguiéndole a distancia el departamento de administración ( $27 \%$ ), y sólo un $20 \%$ cuenta con departamento específico. En cuanto a los fondos documentales, en la mayoría de los casos se inician a partir de 1977, fecha en la que se legalizan las organizaciones empresariales. Tan sólo un $13 \%$ de las organizaciones encuestadas disponen de documentación anterior a esta fecha, destacando entre ellas el archivo de Fomento del Trabajo Nacional con documentación desde el siglo XIX. En cuanto al espacio que ocupa esa documentación, en un $20 \%$ de los casos tiene más de 100 metros lineales de documentación, un porcentaje que se aumenta hasta el $40 \%$ para las que disponen de más de 50 metros lineales. Por lo que respecta al tratamiento de la documentación, el $60 \%$ utiliza algún sistema de clasificación, y un $67 \%$ tiene algún inventario de su documentación. Los problemas espaciales hacen que un $87 \%$ expurgue la documentación En cuanto a los sistemas de reproducción de la documentación el $100 \%$ realizan fotocopias y el $67 \%$ lleva a cabo tareas de digitalización de la documentación. Por lo que respecta a la difusión del archivo y de su documentación, el $40 \%$ nunca ha informado de la existencia del archivo. El $60 \%$ restante ha utilizado medios de difusión internos como son la memoria anual de la institución (53\%), la revista en la que se difunden las noticias de la organización (13\%) y la página web corporativa (27\%). Los usuarios principales son los propios miembros de la organización, haciéndolo de manera esporádica los asociados y de forma excepcional los investigadores. Los principales problemas a los que se enfrentan son la falta de espacio (80\%), carencia de personal especializado (33\%), dificultades para controlar la documentación en soporte digital $(27 \%)$ y para localizar la documentación en papel (20\%).

\subsection{Conclusiones generales}

En conclusión, desde las propias organizaciones empresariales no se ha prestado mucha atención a sus archivos, estando generalizada la ausencia tanto de departamentos específicos encargados de la gestión documental como de personal cualificado al frente de los archivos. Al no haber profesionales trabajando en estos archivos, no se ha desarrollado una práctica archivística que pudiera haber dado lugar a la publicación de instrumentos de descripción sobre sus fondos documentales. Sin práctica archivística, mucho menos ha habido análisis teóricos sobre la documentación producida, las funciones a desarrollar en estos archivos, la metodología a aplicar... Es decir, se carece de una bibliografía específica que pueda guiar las actuaciones a realizar en estos archivos. Por otra parte, el enorme vacío legal en materia documental - al dejar en manos de las propias organizaciones empresariales la decisión sobre que documentación produce, como la organiza y

Scire. $10: 1$ (en.-jun. 2004) 185-216. 


\section{Miguel Ángel del Prado Martínez.}

cuanto tiempo la conserva - dificulta - o más bien impide - establecer a priori un esquema sobre la documentación existente. La ausencia de información sobre estos archivos - no están censados y, por tanto, son una absoluta incógnita para los responsables de las comunidades autónomas - , a la que en buena medida han contribuido las propias organizaciones empresariales al no difundir al exterior sus archivos, hace que sean unos auténticos desconocidos, por lo que los únicos usuarios son los miembros de las organizaciones y en ocasiones las empresas asociadas. A ello también ha contribuido el desinterés de la investigación histórica sobre las organizaciones empresariales. Sin demanda por parte de los investigadores, sin necesidad legal de conservar la documentación y con serios problemas espaciales para conservarla, se hace entendible que la documentación sea destruida una vez perdido su interés para la gestión administrativa, por lo que se corre un serio peligro de desaparición de los fondos documentales con valor histórico.

\section{Propuestas de actuación}

\subsection{Consideraciones previas}

A la luz de la situación en la que se encuentra la Archivística en el ámbito de las organizaciones empresariales, se puede afirmar que está todo por hacer tanto a nivel teórico como práctico. Por ello, es prioritario que se reconozca el valor que el archivo puede alcanzar dentro de una organización empresarial, pues sólo este reconocimiento va a permitir que se destinen los recursos materiales y humanos necesarios para que pueda desarrollar todas sus potencialidades. Y, para que un archivo sea considerado como tal, es necesario que tenga contenido - el conjunto orgánico de documentos producidos por una institución-, un continente - los depósitos documentales - , un personal - los profesionales capacitados científica y técnicamente para las distintas labores archivísticas - , una gestión archivística (recogida, organización, conservación de la documentación - y un servicio documental (Fuster Ruiz, 1999). El fin último es lograr la utilización efectiva y exhaustiva del archivo como recurso básico de información, en primer lugar, para la organización en la que se enclava y, en segundo lugar, para la investigación y la difusión cultural. Para ello, será imprescindible una acción continuada y sistemática, desarrollada por personal capacitado y con el respaldo de la alta dirección.

\subsection{El archivo dentro del sistema informativo de la organización}

El archivo debe ser una pieza fundamental del sistema informativo de una organización. En un anterior trabajo (Prado Martínez, 2002) ya se señaló la necesidad que todas las organizaciones tienen de disponer de información de calidad, y como su carencia tiene repercusiones que pueden ir desde las molestias organizativas hasta la toma de decisiones mal fundamentadas, o incluso el cese de sus actividades, lo que obliga a las organizaciones a dotarse de instrumentos que

Scire. $10: 1$ (en.-jun. 2004) 185-216. 
les permitan satisfacer sus necesidades informativas, y evidentemente el archivo debe ser uno de ellos. Se ha estimado que el $90 \%$ de la información de una organización reside en documentos (Martínez Sánchez, 1997, p. 238), por lo tanto, para conseguir una buena gestión de la información es imprescindible organizar y conseguir un buen sistema de gestión documental. Esto requiere una comprensión de la documentación producida. A grandes rasgos, en una organización podemos diferenciar dos tipos de documentación: a) la documentación generada en el desempeño de sus funciones, como plasmación de las actividades realizadas; y b) las distintas publicaciones o fuentes de información que reciben o incluso elaboran ellas mismas para su difusión pública - libros, revistas, prensa, literatura gris, vídeos, bases de datos, Internet, etc. - - El primer tipo de documentación formará el archivo de la organización y el segundo la biblioteca o centro de documentación, y estos deben ser, por tanto, los auténticos centros neurálgicos de un sistema de información. Por ello, y en la línea marcada tanto por Remei Perpinyà y Núria Rius (1995) como por Mercedes de la Moneda (1995) - y que hemos puesto en práctica en una serie de organizaciones empresariales aragonesas - , creemos que el archivo debe estar integrado junto a la biblioteca y el centro de documentación dentro del sistema de gestión documental de la organización, constituyéndose éste último en el centro neurálgico de su sistema de información.

Por lo tanto, proponemos la creación en las organizaciones empresariales que estén lo suficientemente desarrolladas (confederaciones, federaciones y las asociaciones de mayor tamaño) de un departamento de gestión documental responsable de la selección, recogida, tratamiento, recuperación y difusión de todos los documentos de la organización y de la información que soportan. Funcionalmente, el departamento estará divido en tres unidades: el archivo, la biblioteca y el centro de documentación. Cada una de ellas tendrá unas funciones concretas y utilizará unas técnicas de trabajo especifica, pero compartirán tanto los objetivos - hacer de la información un importante recurso corporativocomo los medios materiales y humanos. Y este último aspecto creo que es vital para que las organizaciones empresariales asuman la contratación de personal cualificado. Teniendo en cuenta las plantillas de las organizaciones empresariales, resulta utópico pretender que creen plazas distintas para archiveros, bibliotecarios y documentalistas. Por ello, será más adecuado pensar en un profesional con un perfil más amplio y flexible, conocedor de todas las técnicas que afectan a la documentación, desde la informática documental a la organización de un centro de documentación, una biblioteca y un archivo.

\subsection{El archivo dentro de la organización y su funcionamiento}

El archivo integrado dentro del sistema de gestión documental de la organización debe ser una pieza fundamental del sistema organizativo y del funciona-

Scire. $10: 1$ (en.-jun. 2004) 185-216. 


\section{Miguel Ángel del Prado Martínez}

miento interno de una organización. El archivo debe garantizar que la documentación este controlada desde su producción hasta su eliminación o conservación permanente, de modo que cada documento esté en el lugar adecuado durante el tiempo estrictamente necesario, y de manera que la información que contiene sea fácilmente accesible a los miembros de la organización.

Muchas son las implicaciones que una correcta gestión documental puede tener para el funcionamiento de una organización empresarial. En primer lugar, le permitiría disponer de manera ágil de la información interna, lo que contribuiría directamente a una mayor eficiencia en el funcionamiento de la organización y a una reducción en el tiempo de trabajo. Así mismo, posibilitaría tanto la reducción de los documentos generados $-\mathrm{y}$ sobre todo reproducidos - como la racionalización y ahorro del espacio físico necesario para almacenarlos.

No obstante, hay que tener presente que el funcionamiento del archivo va a estar condicionado por la organización interna de la institución. Así, las instituciones altamente jerarquizadas suelen ser poco transparentes y tienden a concentrar la documentación de calidad y con más valor informativo en torno a los órganos superiores. Por su parte, las organizaciones con fuerte desarrollo departamental tienden a establecer sistemas documentales estancos. El archivo debe posibilitar que la información se comparta, pero con una política de opacidad y restricciones informativas - con fuerte compartimentación de la información- es difícil establecer un sistema archivístico que tenga por finalidad hacer de la información generada en el interior de la institución un importante recurso corporativo.

\subsection{Concepción global del archivo}

El archivo tiene que tener una visión global que abarque el ciclo vital completo de la documentación desde su producción hasta su eliminación o conservación permanente y que a su vez contemple todos los soportes documentales desde el papel a los documentos electrónicos y las bases de datos.

Aunque el papel ya convive con otros soportes documentales, no solo no está desapareciendo de las organizaciones sino que su volumen crece de manera exponencial. Por paradójico que parezca, a este crecimiento ha contribuido la generación de documentos mediante aplicaciones ofimáticas, debido a las facilidades que ofrecen para su reproducción e impresión. Los documentos electrónicos plantean sus propios problemas. Carlota Bustelo (2000) ya señaló que casi el 100 $\%$ de los documentos se crean en formato electrónico, por lo que su acumulación en los ordenadores dificulta su localización ocasionando problemas importantes de gestión. Además, la facilidad con la que se generan las copias reproduce un caos todavía mayor que el que producen las copias en papel, agravado con la posibilidad de tener un mismo documento en infinitas versiones. Por su parte, la implantación del correo electrónico de forma masiva en las organizaciones lo

Scire. $10: 1$ (en.-jun. 2004) 185-216. 
ha convertido en el medio de comunicación de múltiples actuaciones que en otro contexto se hubieran realizado con documentos en papel, por lo que se hacen necesarias estrategias que permitan que la información intercambiada por correo electrónico o mensajería interna no se pierda y sea accesible para el conjunto de la organización. Tampoco se deben olvidar las múltiples bases de datos generadas por los distintos departamentos de las organizaciones y que en muchos casos están sustituyendo a los documentos como soporte de información.

\subsection{Necesidad de planificar los sistemas archivísticos}

Aceptados estos presupuestos teóricos, debe ser cada organización la que ha de planificar su propio sistema archivístico. La metodología para la planificación de un sistema archivístico empresarial propuesta por Eduardo Núñez Fernández (1999, p. 482-506) nos ofrece un buen modelo a seguir, así como las expuestas por Moneda Corrochano (1995) o Jurado de Baruch (1993). Las fases que este autor señalan son las siguientes:

$1^{a}$ fase. Análisis y Diagnóstico

\subsection{Análisis}

- Análisis de la entidad: historia y evolución, funciones y actividades desarrolladas, organigrama...

- Análisis del fondo documental: dimensiones, condiciones de conservación, grado de normalización...

- Análisis de la organización archivística existente: criterios y técnicas de clasificación, ordenación y descripción de documentos, instrumentos de descripción existentes, criterios para la selección y eliminación de documentos, condiciones de acceso, nivel de informatización...

1.2. Diagnóstico. Elaborar un informe con las conclusiones a las que se ha llegado que se presentará a la dirección.

$2^{\mathrm{a}}$ fase. Proyecto de desarrollo

2.1. Motivación general del proyecto

2.2. Metodología aplicada en el proyecto

2.3. Objetivos generales y concretos del proyecto

2.4. Modelo de sistema archivístico propuesto (fases archivísticas y tipos de archivos)

2.5. Presupuesto y estudio de viabilidad del proyecto

2.6. Temporalización del proceso de implantación del sistema

$3^{\mathrm{a}}$ fase. Presentación y aprobación del proyecto

Scire. $10: 1$ (en.-jun. 2004) 185-216. 
$4^{\text {a }}$ fase. Implantación del sistema

4.1. Fase de información y formación

4.2. Fase de implantación de los archivos de gestión

4.3. Fase de implantación de los archivos centrales

$5^{\text {a }}$ fase. Supervisión y control del sistema archivístico

5.1. Programa de control de calidad

\subsection{Documentación histórica}

Finalmente no hay que olvidar la documentación que ha perdido su valor administrativo, legal o jurídico y que está acumulada en los archivos de las organizaciones empresariales. Se trata de una documentación con evidente riesgo de desaparición, debido a que las organizaciones empresariales no tienen obligaciones legales para conservarlas, a los problemas espaciales en las sedes de las organizaciones dificultan su conservación; y a la carencia de demanda. En este último sentido es necesario señalar que no hay en estos momentos usuarios de esta documentación. En las organizaciones prácticamente nunca se consulta la documentación de más de cinco años de antigüedad, así Manuela Moro Cabero (1997) afirmaba que los responsables de las tomas de decisiones sólo consultan la documentación existente en su despacho o en el de sus colaboradores. Por otra parte, los investigadores tampoco acuden a esta documentación, bien sea por desinterés hacia las organizaciones empresariales, por desconocimiento o por dificultad de acceso. Ya Manuel Titos Martínez (1982) señalaba que difícilmente se puede pedir la conservación de un bagaje considerable de documentación a empresas que generalmente carecen de espacio físico para ello, si no se justifica de algún modo este almacenamiento y más aún, cuando en muchas ocasiones puede resultar un obstáculo espacial para el normal desarrollo de la empresa y que va a ser necesariamente económicamente costoso, por las específicas necesidades que su ubicación requiere y el personal especializado que su tratamiento exige.

Por lo tanto, para actuar sobre esta documentación es necesario que previamente se le reconozca algún valor, y el principal valor de esta documentación es de fuente de información para la investigación histórica. Las asociaciones empresariales tienen un indudable interés como materia de estudio, dado su papel como interlocutores ante los poderes públicos, las fuerzas sindicales, y organismos sociales y culturales, así como por su influencia en la conformación de determinadas políticas públicas y en los cauces para ejercerlas. Disciplinas como la Sociología, las Ciencias Políticas o la Historiografía (especialmente la Historia Económica y Social), y los estudiosos de las relaciones industriales y del Derecho del Trabajo encontrarán en las organizaciones empresariales un importante campo de investigación.

Scire. $10: 1$ (en.-jun. 2004) 185-216. 
No obstante, el asociacionismo empresarial ha sido escasamente investigado, y hay una grave carencia de estudios monográficos. Entre las posibles causas del desinterés de los estudiosos por el mundo empresarial García Femenía (2002, p. 27-38) ha señalado la propia actitud de los empresarios y sus asociaciones, acusados de ser poco generosos a la hora de procurar información sobre sí mismos. También se ha destacado la atracción que han tenido los científicos sociales por los trabajadores y los sindicatos en detrimento de los empresarios y sus organizaciones, generalizándose la idea de que las organizaciones empresariales han tenido una actuación menor en el sistema de relaciones laborales, una actuación simplemente reactiva frente a los sindicatos, a los que en determinado ámbitos se consideran los verdaderos actores sociales. Siguiendo las conclusiones a las que llega García Femenía, el mundo de los empresarios y de sus organizaciones ha sufrido las consecuencias de su exigua consideración, en lo que han influido determinados planteamientos ideológicos, así como la extendida desconfianza hacia el mundo empresarial. De esta manera, las organizaciones empresariales han pasado de ser poco conocidas a ser poco apreciadas y en ocasiones denostadas por un público poco proclive a prestarles mayor atención. Por ello, deberían ser las propias organizaciones empresariales las principales impulsoras de los estudios sobre sus actuaciones, fundamentalmente para potenciar una imagen positiva. A su vez, el conocimiento de las trayectorias seguidas contribuirá a descubrir las señas de identidad de cada organización. La reconstrucción de un pasado histórico brillante y lleno de experiencias puede ser un magnífico instrumento de publicidad que avale la solvencia y calidad de los servicios prestados. Desde esta perspectiva los archivos se pueden convertir en un factor de prestigio corporativo dentro de la política de marketing que permite mejorar su imagen, reconstruir su historia y crear su propia identidad cultural y social.

Reconocido el valor de la documentación histórica, se hace preciso arbitrar medidas que posibiliten su conservación y puesta en servicio. En nuestra opinión son tres las opciones existentes. La primera conservar la documentación en las propias organizaciones empresariales. Para ello, deberían contar con depósitos documentales dotados de las medidas de preservación adecuadas para garantizar la conservación futura de la documentación, y con unas dimensiones en consonancia con el volumen documental existente y el crecimiento previsible en un plazo prudencial. La segunda opción es transferir la documentación histórica desde las organizaciones empresariales a archivos históricos, ya sean públicos o privados. Un modelo a seguir puede ser el de los archivos de los sindicatos y partidos políticos, los cuales, tras su legalización con la recuperación democrática, constituyeron una serie de fundaciones cuya finalidad fundamental era la conservación, organización y difusión de sus archivos (Vázquez de Parga y Sierra Barcena, 1997). De esta manera, se crearon una serie de archivos históricos (8) para recoger

Scire. $10: 1$ (en.-jun. 2004) 185-216. 


\section{0}

Miguel Ángel del Prado Martínez.

la documentación de los respectivos sindicatos y partidos políticos, a los que se les dotó de recursos materiales y personales, abriéndolos a la investigación.

Se trataría de que las organizaciones empresariales con algún punto de interés coincidente - sector de actividad, ámbito geográfico en el que radican...- creasen fundaciones que tuviesen como objetivo el desarrollo de actividades culturales que permitieran difundir una imagen socialmente positiva de los empresarios, y en la que ocuparía un lugar central el archivo histórico de las organizaciones empresariales como centro encargado de recoger toda la documentación histórica transferida desde las distintas asociaciones empresariales, de organizarla de acuerdo a criterios archivísticos normalizados, y de prestar los servicios de acceso y difusión de la documentación. Las ventajas de la creación de estos archivos históricos son indudables. Las organizaciones empresariales se verían liberadas de un volumen importante de documentación al transferirla a estos archivos. Se posibilitaría la conservación de una documentación que de otra manera sería destruida. La concentración de recursos permitirá dotar a estos archivos tanto de personal cualificado como de los medios materiales necesarios. La concentración de la documentación facilitaría el estudio a los investigadores al disponer en un único centro de la documentación de varias organizaciones empresariales. Así mismo, facilitaría la normalización del tratamiento archivístico. No obstante los problemas para conseguirlos no son pocos. Así, a diferencia del movimiento sindical, el asociacionismo empresarial ha dado lugar a una multiplicidad de organizaciones empresariales todas ellas con personalidad jurídica propia, con unos intereses y objetivos propios, lo que dificulta llegar a los necesarios acuerdos. Otro problema es el financiero, pues evidentemente un proyecto de está envergadura necesita de una importante financiación para la construcción o adecuación de un edificio para archivo, para dotarlo de instalaciones y mobiliario adecuado, para la contratación de personal, para su posterior mantenimiento... Por ello, no sólo serán necesarias las aportaciones de las organizaciones empresariales, sino que se debería contar con la ayuda económica de las distintas administraciones públicas de acuerdo con el interés general de este tipo de proyectos.

Por último, la tercera opción sería la digitalización de la documentación con valor histórico e informativo antes de su destrucción, creando archivos virtuales.

\section{Notas}

(1) Federación de Empresarios de Comercio de Huesca, Confederación Empresarial de la Provincia de Huesca, Asociación de Empresarios-Instaladores de Saneamiento de Huesca, Federación de Empresarios del Metal de Huesca, Asociación Provincial de Empresarios de Hostelería de Huesca, Asociación Provincial Empresarial de Electrotecnia de Huesca, Asociación de Transportes de Huesca, Agrupación Provincial Empresarial de Carniceros-Salchicheros de Huesca, Federación 
Empresarial de Hostelería de Orense, Asociación Empresarial de Autoescuelas de Orense, y Confederación Empresarial de Orense.

(2) Asociación Comarcal de Empresarios de Hostelería, Elda (Alicante); Asociación de Armadores de Buques de Pesca al Fresco, El Puerto de Santa María (Cádiz); Asociación de Consignatarios de Buques y Empresas Portuarias de Málaga; Asociación de Detallistas de Mercados, Cádiz; Asociación de Empresarios de la Construcción, Lugo; Asociación de Empresarios del Metal, Elche (Alicante); Asociación de Empresarios Textiles, Alcoy (Alicante); Asociación de Fabricantes Importadores, Pedreguer (Alicante); Asociación de Hostelería de Logroño; Asociación de Promotores y Constructores (ASPRÓCON), Gijón (Asturias); Asociación de Promotores y Constructores de Obras, Jaén; Asociación de Transportistas de Mercancías, Jaén; Asociación Empresarial de Agencias de Viajes, Benidorm (Alicante); Asociación Española de Fabricantes de Azulejos, Pavimentos - Baldosas y cerámicos, Onda (Castellón); Asociación Profesional CarnicerosCharcuteros de Orihuela (Alicante); Asociación Profesional de Representantes de Comercio (Jaén); Asociación Provincial de Empresarios de Hostelería de Lugo; Asociación Provincial de Empresarios de Piedra, Granito y Mármol de Novelda (Alicante); Asociación Provincial de Fabricantes de Alfombras y Afines (AFAYA), Crevillente (Alicante); Asociación Provincial de Talleres de Reparación de Vehículos, Orense; Asociación Provincial de Transportes de Viajeros, Lugo; Confederación Empresarial de la Provincia de Cádiz; Confederación Castellonense de la Pequeña y Mediana Empresa (PYMEC), Castellón; Federación de Comercio y Artesanado, Villareal (Castellón); Federación de Empresarios, Logroño; Federación Empresarial Jinenense, Jaén; Gremio de Industriales Panaderos, Valencia; y Gremios Patronales, Vendrell (Tarragona).

(3) Confederación Empresarial Malagueña, Federación de Organizaciones Empresariales Sorianas, y Asociación de la Industria Navarra.

(4) Es el caso de los archivos histórico comarcales de la Bisbal d'Empordà, Figueras, Igualada, Olot, Puigcerdà y Santa Coloma de Farners. De la organización sindical también se conserva documentación en el Dipòsit d'Arxius de Cervera y en los archivos histórico provinciales de Girona, Lleida y Tarragona.

(5) Es el caso de los archivos histórico comarcales de Balaguer, Berga, Cervera, Olot, Reus, Terrassa, Terres de l'Ebre y Vilafranca del Penedès.

(6) Es la fuente de información más exhaustiva que en la actualidad disponemos, con un catálogo que recoge todas las publicaciones de la biblioteca del CIDA, así como los artículos de revistas y de publicaciones misceláneas. Cuenta con unos 35.000 registros, de los que alrededor de 9.000 corresponden a censos, guías, catálogos e inventarios de todos los archivos españoles, así como de los principales archivos extranjeros. Destaca la información detallada que proporciona del contenido y tipología de cada publicación a través de materias y descriptores.

(7) Los archivos que relaciona son: Cambra oficial de Comerç i Navegació, de Barcelona; Foment del Treball Nacional, de Barcelona; Institut Agrícola Català de Sant Isidro, de Barcelona; Institut d'Invesigacions Econòmiques, de Barceolona; Col.legi d'Agents de Canvi i Borsa (Llojta); Societat Económica Barcelonesa de d'Amics del Pais;

Scire. $10: 1$ (en.-jun. 2004) 185-216. 
Caixa d'Estalvis i Mont de Pietat, avui Caixa de Barcelona ; Centre Autonomista de Dependents del Comerç i la Indústria (CADCI); Arxius de les Societats Industrials Maquinista Terrestre y Maritima, S. A. i de la España Industrial; y Delegació d'Hisenda de Barcelona.

(8) Fundación $1^{\circ}$ de Mayo, el Archivo Histórico de CC.OO; Fundación Largo Caballero, Archivo Histórico de UGT; Fundación de Estudios Libertarios "Anselmo Lorenzo", CNT-AIT; Fundación Pablo Iglesias, Archivo Histórico del PSOE; Fundación José Barreiro (Oviedo), Archivo Histórico del PSOE Asturiano; Fundación de Investigaciones Marxistas, Archivo Histórico del PCE; y Fundación Humanismo y Democracia, UCD.

\section{Referencias}

Agenda Administrativa [: servicios de Archivo] [en línea]. Zaragoza: Gobiernode Aragón, Departamento de Presidencia y Relaciones Institucionales URI C http. Lotalaragohes/coi-hin/agen $/ B R S C G L P C M D=V E R I S T \& B A S E=A G E N \& D O C S=$ $1-100 \& 0 P D E F=\% 26 \& \mathrm{FMT}=A$ GENPORTAL $\mathrm{pff} \& \mathrm{SORT}=$ MUNI,CENT \&SEPAR ADOR=\&GENE-C=centro\&OP1=Y\&GENE-C=archivo 7. Consulta: 3 mayo 2005.

Archivo General de la Región de Murcia [en línea]. Murcia: Comunidad Autónomade la Región de_Murcia,_Consejería_de_Educación y Cultura. URL: \ttp://www.carm.es/ educacion/archivoregional/archivoregional.htmp. Consulta: 3 mayo 2005.

Archivo General de Navarra [en línea] Pamplona. Gohierno de Navarra URL. http. /www navarra_es/nr/navarra/asp/redirect.asp?sUrl=http\%3A\%2F\%2Fwww\%2 Ecfn avarra\%2Ees\%2Fagn\%2F\&f=True . Consulta: 3 mayo 2005.

Archivo Histórico de Protocolos de Madrid [en línea] Madrid. Servicio_Regionalde Archivos de la Comunidad_de_Madrig. URL: \&ttp://www.madrid.org/clas_artes/ archivos/centros/archivo_historico.htmp. Consulta: 3 mayo 2005.

Archivo Histórico Provincia_de_Cantahria_en línea] Santander. Gohierno de Cantabria 2003 URL $<$ http.//www gohcantahria_es/portal/page? pageid=33,31132\&_ dad=interportal\&_schema=INTERPORTAL\&item_id=146181\&group_$\mathrm{d}=33 \&$ page_id=41635P. Consulta: 3 mayo 2005.

Archivo Histórico Provincial de Huesca [en línea]. Zaragoza: Gobierno de Aragón DepartamentodeEducación, Cultura y Deportes, $2003 \mathrm{URL} \cdot<\mathrm{http} / \mathrm{portal}$ aragoh es servlet/page? pageid $=4551 \&$ \&ad $=$ portal $30 \&$ schema $=P O R T A \perp 30 \&$ type $=$ site $\&$ Esiteid $=967 \&$ fid $=1334704 \&$ fnavbarid $=1 \&$ fnavbarsiteid=967\&_fedit $=0 \&$ \&mode=2\&_fdisplaymode $=1 \& \_$fcalledfrom $=1 \& \_$fdisplayurl $=>$. Consulta: 3 mayo 2005 .

Archivo Histórico Provincial de Santa Cruz de Tenerife [en línea]. Las Palmas de Gran Canaria. Gobiernode Canarias, Consejería de Educación, Cultura y Deportes. URL: $<$ http://www.culturadecanarias.com/ahptf/P. Consulta: 3 mayo 2005.

Archivo Histórico Provincial de Teruel [en línea]. Zaragoza:Gohierno de Aragón Departamento de Edwcación, Cultwra y Deportes URI.<http.//portal aragohes servlet/page?_pageid=576,599\&_dad=portal30\&_schema=PORTAL30\&cuerpo.est =ITPG_CT_ARCTERP. Consulta: 3 mayo 2005. 
Archivo Histórico Provincial de Zaragoza [en línea]. Zaragoza· Gobierno de Aragón, Departamento de Edwcación, Cultwra y Deportes URL • < http./portal aragohess servlet/page?_pageid=576,599\&_dad=portal30\&_schema=PORTAL30\&cuerpo.est =ITPG_CT_ARCZAR . Consulta: 3 mayo 2005.

Archivo Histórico Provincial Joaquín Blanco [en línea]. Las Palmas de Gran Canaria. Gohierno de Canarias, Consejería de Educación, Cultura y Deportes. URL: < http: /www.culturadecanarias.com/ahppl/P. Consulta: 3 mayo 2005.

Archivo Regional de la Comunidad de Madrid [en línea] Madrid. Servicio Regionalde Archivos de la Cammidad de Madrid. URL: http://www.madrid.org/clas_artes/ archivos/centros/archivo_regional.htmP. Consulta: 3 mayo 2005.

Archivas Municipales [en _ínea]_Logroño Archivo_Generalde La Rioja, 2005 URL. http//lias1.larioja.org/arm/consulta/principal.jsp?idSesionVirtual=1115119230322 \&tipo=2 7 . Consulta: 3 mayo 2005.

Arquivo do Reino de Galicia [en línea]. Santiago de Compostela· Xunta_de Galicia Consellería de Cultura, Comunicación Sociale Turismo URL: http://www.xunta.es/ conselle/cultura/patrimonio/arquivo\%20reino/index.htmp. Consulta: 3 mayo 2005.

Arquivo Histórico Provincial de Lugo [en línea]. Santiago de Compostela: Xunta_de Galicia, Consellería de Cultura, Commicación_Sociale Turismo. URL: 〈http: //www.xunta.es/conselle/cultura/patrimonio/lugo/index.htmp. Consulta: 3 mayo 2005.

Arquivo Histórico Provincial de Ourense [en línea]. Santiago de Compostela: Xunta de Galicia, Consellería de Cultura, Comunicación Sociale Turismo. URL: 〈http: //www.xunta.es/conselle/cultura/patrimonio/ourense/index.htmp. Consulta: 3 mayo 2005.

Arquivo Histórico Provincial de Pontevedra [en línea]. Santiago de Compostela: Xunta de Galicia, Consellería de Cultura, Comunicación Sociale Turismo URL C htp: //www.xunta.es/conselle/cultura/patrimonio/arquivo\%20pontevedra/ah_g.htmp. Consulta: 3 mayo 2005.

Arxius de Catalunya [en línea] Barcelona· Generalitat de Catalunya, Departament de Cultura. URL: < http://cultura.gencat.net/arxius/directori.aspp. Consulta: 3 mayo 2005.

Badator: Sistema de Información sobre los Servicios de Archivo y los inventarios de sus Fondos [en línea]. Bergara(Guipúzcoa)·IRARGLCentrode Patrimonjo Documental de Euskadi. URL: 〈http://www.irargi.org/badator/01doc_badator.htm〉. Consulta: 3 mayo 2005.

Bibiano, José. Programa del curso de doctorado Documentos y archivps de relaciones laborales Getafe-Universidad Carlos Wde Madrid, [s d.] URL: \http://www.uc3m.es/ uc3m/gral/TC/ESDO/esdo03programababiano.htmp. Consulta: 15 de julio de 2003 Bibliografía de archivos. en linea.. Madrid: Centro de Información y

Bustelo Ruesta, Carlota (2000). Gestión documental en las empresas: una aproximación práctica. // Actas de las VII Jornadas Españolas de Documentación FESABID 2000. 189-195. 


\section{Miguel Ángel del Prado Martínez}

Cantín Luna, Inmaculada; Cantín Luna, Matilde; Orera Orera, Luisa (1996). Catálogo de obras de referencia de la Biblioteca General Universitaria: Bibljografías y catálogos en línea I/ Zaragoza. Universidad deZaragoza, 1996. URL: 〈http://wzar.unizar.es/ doc/buz/catref/b14.htmp. Consulta: 25 abr. 2005.

Catálogo del Archivo y Biblioteca del Instituto de Fomento del Trabajo Nacional. Barcelona, 1883.

Cénsara: Base de datos del Censo de Archivos Andaluces [en_línea] Sevilla. Archivg Generalde_Andalucía. URL: < http://www.juntadeandalucia.es/cultura/aga/Censara/ Menucensara.jsp. $>$. Consulta: 3 mayo 2005.

Censo Guía de Archivos de España e Iberoamérica. en línea.. Madrid:

Comisión Técnica de Archivos Históricos de la Anabad (1994). Organización de Fondos de los Archivos Histórico Provinciales. Madrid: ANABAD, 1994.

Corral, Ma Aurelia (1980). Transferencia de documentos de la AISS a la administración central. // Boletín de la ANABAD. XXX : 4 (1980). 545-558.

Directorio de Archivos de la Región de Murcia [en línea]. Murcia: Comunidad Autónoma_e la Región de Murcia_Consejería_e_Educación y Cultura. URL: 〈http: /www.carm.es/educacion/archivoregional/directorioarchivos.html . Consulta: 3 mayo 2005.

Documentación de Archivos_URI. · th.//www mcu.es/archivos/jsp/plantillaAncho.jsp? $\mathrm{d}=15 \&$ contenido=/archivos/ba/formulario.jsp .. Consulta: 25 abr. 2005.

Fernández Izquierdo, Francisco; Tosete Herranz, Francisco. Arxiu del Regne de Mallorca [en_línea] Palma_de Maلlorca. Govern_de_les_lles_Balears 2000. URL: http: /www.caib.es/conselleries/educacio/arxregne/web/default.htmp. Consulta: 3 mayo 2005.

Fernández Trabal, Joseph (1996). Los archivos empresariales en Cataluña: balance de 15 años de actuación del Arxiu Nacional de Catalunya. // Revista de Historia Industrial. 9 (1996) 183-198.

Fuster Ruiz, Francisco (1999). Archivística, archivo, documento de archivo... necesidad de clarificar los conceptos // Anales de documentación. 2 (1999). 103-120.

García Femenía, Ana María (2002). El asociacionismo empresarial en España. Madrid: Instituto de Estudios Económicos, 2002.

Grupo de Trabajo sobre la Administración Institucional de Servicios Socio-Profesionales (AISS) (1992). La organización sindical española: 1938-1977. // Actas de las primeras jornadas sobre metodología para la identificación y valoración de fondos documentales de las administraciones públicas. Madrid, Dirección de los Archivos Estatales, 1992. 71-91.

Guía de las organizaciones empresariales Españolas. Madrid: Doxa, 1999.

Gutiérrez Álvarez, Secundino José (2001). Aproximación a las organizaciones empresariales en España. Madrid: Fundación CEIM, 2001.

Jurado de Baruch, $\mathbf{M}^{\mathrm{a}}$ Teresa (1993). Organització del arxius a les empreses. // Lligall. 7 (1993). 181-222. 
Legislación hásica [en línea] Alicante-Universidad de Alicante,Archivo General. URL: http://www.ua.es/es/bibliotecas/archivo_generaln/legislacionn/ $>$. Consulta: 25 abr. 2005.

Legislación cultural archivos [en línea] Madrid. Ministerio de Cultura. URL: http: /www.mcu.es/jsp/plantilla_wai.jsp?id=14\&area=legislacion $>$. [Consulta: 25 abr. 2005.

Maluquer de Motes, Jordi, (1983). Archivos de corporaciones económicas: el Fomento de Trabajo Nacional. // Actas del I Congreso sobre archivos económicos de entidades privadas. Madrid: Banco de España, 1983. 85-87.

Martínez Sánchez, José Manuel; Hilera Sánchez, José Ramón (1997). Los sistemas de gestión documental en el ámbito del trabajo corporativo. // Documentación de las ciencias de la información. 7 (1997). 237-255.

Minjsterio de Cultura, Subdirección_General de los Archivos Estatales. URL: <http: /aer.mcu.es/sgae/index_censo_guia.jsp P. Consulta: 25 abr. 2005.

Moneda Corrochano, Mercedes de la (1995). El archivo de empresa: un concepto integrado // Manual de archivística. Madrid: Síntesis, 1995. 235-262.

Moro Cabero, Manuela (1997). El archivo de empresa: un recurso a considerar desde la perspectiva TQM (Total Quality Management). // Revista general de información y documentación. 7:2 (1997). 257-275.

Navarro Bonilla, Diego (1998). Los archivos de empresa: aproximación a la normativa jurídica reguladora de la producción documental en las empresas españolas. // Boletín de ANABAD. 48 (1998). 49-75.

Navarro Gomollón, Ángel J.; Navarro Lima, Jaime J. (2003). Aspectos contables y fiscales de las asociaciones empresariales: situación actual (primera parte). // Boletín informativo para la empresa. Zaragoza: CEPYME ARAGÓN; FEMZ. 9 (feb. 2003) 15.

Núñez Fernández, Eduardo (1999). Organización y gestión de Archivos. Gijón: Trea, 1999.

Perpinyà i Morera, Remei; Rius i Vera, Núria (1995). El sistema documental de l'empresa: el punt de vista de l'arxiu i el centre de documentació. // V Jornadas Catalanas de Documentación. Barcelona: COBDC : SOCADI, 1995. 337-344.

Prado Martínez, Miguel Ángel del (2002). El servicio de documentación en las organizaciones empresariales. // Scire, 8:2 (jul.-dic. 2002) 173-188.

Sobreques i Callicó, Jaime (1982). Els arxius per a la història del nacionalismo cátala. Barcelona: Departament de Cultura de la Generalitat de Catalunya, 1982.

Titos Martínez, Manuel (1982). Los archivos empresariales y la investigación histórica. // Anuario de Historia Contemporánea. 9 (1982). 235-252.

Vazquez de Parga, Margarita; Sierra Barcena, Carmen (1997). La conservación de los archivos históricos de los partidos políticos españoles: la acción de tutela del Estado. // Boletín de la ANABAD. 47 (1) (1997) 57-75. 